\title{
PAVIMENTAÇÃO RODOVIÁRIA: UMA ANÁLISE DE QUAL MELHOR TIPO DE PAVIMENTAÇÃO PARA AS RODOVIAS BRASILEIRAS
}

\author{
ROAD PAVING: AN ANALYSIS OF WHAT BEST TYPE OF PAVING FOR \\ BRAZILIAN ROADS
}

\author{
Pedro Emílio Amador Salomão, \\ Doutor, Faculdade Presidente Antônio Carlos de Teófilo Otoni, Brasil. \\ pedroemilioamador@yahoo.com.br \\ Luann Marco Moreira Fróes, \\ Bacharel, Faculdade Presidente Antônio Carlos de Teófilo Otoni, Brasil. \\ luann_marco@hotmail.com
}

Recebido: 10/11/2020 - Aceito: 27/11/2020

\section{Resumo}

As rodovias brasileiras desempenham grande importância econômica para o país, por tanto este trabalho trata da avaliação das condições do pavimento das rodovias brasileiras. Com o tráfego pesado e intenso nas ruas, os problemas surgem constantemente, as ruas e rodovias estão degradadas, são péssimas as condições de conservação das rodovias na atualidade. É visível a necessidade de melhoria no sistema viário, para todos os setores da economia e da sociedade em geral. Uma boa pavimentação requer uma adequada estrutura, porém para que essa estrutura seja realizada da maneira correta alguns pontos devem ser observados, principalmente em relação dos custos/benefícios oferecidos por cada tipo de pavimento existente. Baseado neste contexto, o trabalho objetiva estudar os tipos existentes de pavimentação rodoviária, observando aos métodos utilizados em cada tipo de resíduo, desempenho e suas principais características, analisar o custo benefício dentre os tipos estudados, e apresentar qual é o melhor tipo de pavimentação para as rodovias brasileiras.

Palavras-chave: Pavimentação asfáltica; rodovias; pavimentos; pavimentação rígida; pavimentação flexível.

\section{Abstract}

As Brazilian highways play a major economic importance for the country, this paper deals with the evaluation of paving conditions of Brazilian highways. With heavy and heavy traffic on the streets, problems arise, as streets and highways are degraded, are terrible as conditions for the conservation of highways today. The need to improve the road system is visible to all sectors of the economy and society in general. Good paving requires an adequate structure, but in order for this structure to be executed correctly, some points must be observed, especially in relation to the cost / benefit ratio offered by each existing pavement type. In this context, the objective work studies the types of road 
paving, observing the methods used in each type of waste, the performance and the main characteristics, analyzing the benefit or benefit of the studied types, and showing what is the best type of paving for how Brazilian highways.

Keywords: Asphalt paving; highways; floors; rigid paving; flexible paving

\section{Introdução}

De extrema importância, a pavimentação significa muito para a população, com a globalização, se tornou indispensável para que ocorra a locomoção com agilidade e segurança. Infelizmente não são todos os locais que possuem uma pavimentação adequada, e em muitos não possuem nem um tipo, entre tanto é de extrema importância que o projeto de pavimentação deva ser bem estruturado e bem executado, para que possa trazer benefícios para toda a população, não apenas para os motoristas.

Com o crescimento do desenvolvimento tecnológico e econômico, o trânsito vem ficando cada vez mais danificado nos trechos urbanos, já que o número de veículos trafegando pelas rodovias e ruas aumentou consideravelmente. Como há trafego intenso e pesado nas ruas, os problemas constantemente aparecem, vários buracos vão surgindo ou crescendo nas vias, e as intervenções para sua manutenção causam muito transtorno a todos.

Para uma boa pavimentação é fundamental observar a relação dos custos/benefícios oferecidos por cada tipo de pavimento existente. Muito utilizado em rodovias, o pavimento de concreto é o que demostra apresentar os melhores custos/benefícios, pois tem uma vida útil superior quando comparada com outros pavimentos, ele é mais resistente, além disso esse tipo de pavimento proporciona uma grande economia de combustível e qualidade, e ainda sofre pouco com deformações plásticas e buracos, por isso, além de ser muito utilizados nas rodovias, também é usado em portos, corredores de ônibus e aeroportos.

Por ser um setor gerenciado pela administração pública o setor de pavimentação, deve ter gestores que além de trabalhar com responsabilidade, visem zelar por esse patrimônio de valor inestimável, pois além de considerarmos o seu valor financeiro, vemos a sua grande importância para as pessoas.

Além da reduzida dimensão da malha rodoviária, a falta de recursos que são investidos na atividade de manutenção e reabilitação de pavimentos reflete-se na condição superficial dos pavimentos: buracos, enormes trincamentos, grandes 
deformações permanentes, entre outros defeitos. Além disso, nas últimas décadas foi dada pouca atenção para a infraestrutura das rodovias, um fato que se acentua pela grande parte das rodovias pavimentadas existentes terem sido construídas em uma época que não eram feitos estudos e não se dava atenção à qualidade dos materiais constituintes do pavimento, bem como à estrutura projetada. Tudo isso contribuiu para as péssimas condições de conservação das rodovias na atualidade.

Dessa forma, os questionamentos que procuramos aqui responder, traçando um paralelo entre os tipos existentes de pavimentação rodoviária e os utilizados nas rodovias brasileiras, e qual é o melhor tipo a ser usando quando analisamos o custo benefício?

\subsection{Objetivos}

\subsubsection{Objetivos Gerais}

Este trabalho tem como objetivo estudar os tipos existentes de pavimentação rodoviária, observando os métodos utilizados em cada tipo de resíduo, desempenho, suas principais características, analisar o custo benefício dentre os tipos estudados, e apresentar qual é o melhor tipo de pavimentação para as rodovias brasileiras.

\subsubsection{Objetivos Específicos}

- Pesquisar quais os tipos de pavimentação rodoviárias existentes;

- Pesquisar as principais tecnologias aplicadas atualmente nas pavimentações rodoviárias;

- Conhecer a estrutura da pavimentação asfáltica;

- Analisar através da comparação de custos de execução e manutenção, qual o melhor tipo de pavimentação para as rodovias brasileiras.

\section{Revisão da Literatura}

\subsection{A pavimentação asfáltica no Brasil}

O homem sempre foi movido pelo conhecimento, e para tanto era necessário sair 
da sua zona de conforto e procurar novos lugares para morar, comer, ou até mesmo para ter contato com outras pessoas. Para que eles não se perdessem foi necessário abrir passagem, e com isso surgiu às primeiras trilhas. Com o passar do tempo e com evolução do homem, essas trilhas começaram a ser usadas com mais frequência, e tiveram que ser melhoradas, alargadas para que os animais pudessem passar com as carroças. O começo da construção de rodovias coincidiu com o surgimento dos primeiros veículos de rodas.

No período Imperial, o visionário Barão de Mauá, construiu a primeira estrada de Ferro do Brasil, com o intuito de que o país desenvolvesse infraestrutura, ele queria garantir meios para o progresso material da nação, meios esses que promovessem a integração do imenso território e que preservassem a sua unidade. Inaugurada em 1854, a estrada de ferro tinha uma extensão de cerca de 15 quilômetros, e ligava o Porto de Mauá e Fragoso que ficava nas dependências do município de Magá.

A primeira rodovia pavimentada do país foi inaugurada por Dom Pedro II em 23 de junho de 1861, o trecho liga Petrópolis - RJ a Juiz de Fora - MG. A rodovia foi pavimentada com a mão de obra dos colonos alemães, que usaram do método macadame, ou seja, um piso composto por pequenas pedras que eram comprimidas de uma forma a se encaixarem umas nas outras. (QUINTIERE, 2011)

A estrada foi de suma importância para o escoamento da produção de café da região além de representar um grande avanço da técnica de engenharia no Brasil, já que ela unia os estados de Minas Gerais e Rio de Janeiro. A rodovia ficou conhecida como "A Primeira Estrada de Rodagem do Brasil".

Somente em 1905 foi aprovada uma lei para conceder auxilio federal para que fossem construídas estradas, entre tanto, apenas em 1920 a Inspetoria Federal de Obras contra as Secas, que era um órgão público, passou a cuidar da criação de rodovias, iniciando seu trabalho no nordeste e sem finalidade especificadamente rodoviária. Em busca do progresso, São Paulo, em 1926, criou a Diretoria de Estradas de Rodagem, que em 1934 se transformou no Departamento de Estradas de Rodagem, este foi o primeiro órgão rodoviário brasileiro com autonomia técnica e administrativa.

Em 1937 foi criado o DNER (Departamento Nacional de Estradas de Rodagem), um órgão federal que ficou responsável pela manutenção, construção, fiscalização, ampliação e elaboração de estudos técnicos de qualquer problema relacionado ao 
tráfego nos transportes terrestres e aquáticos do país. Em 2001 o órgão mudou o nome para DNIT (Departamento Nacional de Infraestrutura de Transportes) que continuou com as mesmas funções e complementou com algumas novas.

\subsection{Aspectos gerais sobre Pavimentação}

\subsubsection{O que é um pavimento}

A palavra pavimento se refere a toda estrutura existente nas ruas feitas para a locomoção de pessoas, carros, bicicletas, entre outros, desta forma podemos conceituar pavimento como uma estrutura com várias camadas de espessuras limitadas, construída em cima de uma superfície final de terraplenagem, destinada economicamente e tecnicamente a suportar ao peso dos veículos que trafegam por ela o clima, procurando propiciar aos usuários melhoria nas condições de rolamento, com economia, conforto e segurança.

Neste sentido segundo Bernucci et al. (2006), pavimento é:

[...] uma estrutura de múltiplas camadas de espessuras finitas, construída sobre a superfície final de terraplenagem, destinada técnica e economicamente a resistir aos esforços oriundos do tráfego de veículos e do clima, e a propiciar aos usuários melhoria nas condições de rolamento, com conforto, economia e segurança.

O pavimento é uma estrutura projetada para suportar impactos provocados pelo trafego de veículos automotores, pelas variações climáticas e pelas chuvas, oferecendo, assim, condições de conforto e segurança aos usuários (CNT, 2007). Segundo Pinto et al (2002), pavimento rodoviário é uma estrutura constituída por uma ou mais camadas, como características para receber as cargas aplicadas na superfície e distribuídas de modo que as tensões resultantes fiquem abaixo das tensões admissíveis dos materiais que constituem a estrutura.

\subsubsection{Materiais}

Para que seja realizada a pavimentação correta, deverá ser observado qual o 
tipo de camada ou o tipo pavimento serão necessárias para a confecção da obra, pois existem diversos tipos de materiais. Para a base, sub-base ou reforço do subleito, os materiais utilizados, são classificados de acordo com o seu comportamento e a sua natureza.

Entre os materiais mais utilizados estão:

- Brita Graduada simples: derivada de uma mistura de produtos de britagem de rocha sã que é feita nas usinas, resultando em um enquadramento em forma de faixa granulométrica contínua, sendo que ao ser compactado de forma correta, transformase em um produto durável e estável.

- Macadame hidráulico: sua composição é à base de água, agregado graúdo e agregado miúdo, desta forma suas camadas são de agregados compactados e tem seus espaços vazios preenchidos por água.

- Macadame seco: assim como o macadame hidráulico usa de agregados graúdos e miúdos, entretanto não usa a água para preencher os seus vazios.

- Solo agregado: composto por solo, água e agregados, que serão aplicados diretamente ao solo e sendo compactado por um rolo posteriormente.

- Rachão: muito utilizado como um reforço para o subleito ou a sub-base, é um material bruto, que é empregado mediante a necessidade de aumento da resistência da camada, são em sua maior parte pedregulhos de dimensões grandes.

Como última camada da estrutura existe o revestimento, é ele que recebe o impacto direto advindo do trafego, e ela é ligada diretamente a qualidade do subleito, por tanto, para que seja camada seja adequada e resistente, podemos usar os seguintes materiais:

- $\quad$ Asfalto: dentre os mais utilizados nas pavimentações podemos destacar três tipos:

- Cimentos asfálticos - Este asfalto muitas vezes é proveniente de matérias como o asfalto natural, comum em jazidas, ou da exsudação do petróleo em refinarias. Sua obtenção é direcionada especificamente para a apresentação de novos aspectos favoráveis para sua utilidade na estrutura de construções pavimentares. (PINTO E PINTO, 2015).

- Asfaltos diluídos - o asfalto diluído, também conhecido como cut-backs, são na verdade, resultado de um processo diluição de cimentos asfálticos, gerada a partir do 
uso de solventes derivados do petróleo de volatilidade adequada, caso utilizar um aquecimento moderado ou eliminar o aquecimento do CAP se torne necessário. (PINTO E PINTO, 2015).

- Emulsões asfálticas - é uma separação coloidal de uma fase asfáltica em uma fase líquida (direta) ou, então, de uma fase aquosa dispersa em uma fase asfáltica (inversa), sobre a influência de um determinado agente emulsificante, obtido através da combinação do asfalto aquecido com a água, juntamente a uma intensa agitação e na presença dos emulsificantes, cujos principais objetivos são gerar estabilidade ao conjunto, envolver os glóbulos de betume por uma película, os mantendo em suspensão e proporcionar a dispersão (PINTO E PINTO, 2015).

- Cimento: Será utilizado o cimento Portland como base no desenvolvimento dos componentes das camadas de revestimento, para os pavimentos rígidos. De acordo com a NORMA DNIT 059/2004 - ES, o cimento Portland poderá ser de qualquer tipo, desde que cumpra com as normas descritas no DNER-EM036.

\subsubsection{Camadas}

A estrutura do pavimento é gerada a partir de algumas camadas, que há de serem constituídas após a terraplenagem da área, acima do subleito, variando de acordo com o trafego no local. O subleito estará abaixo de toda a estrutura do pavimento, agindo como a fundação do sistema que será o receptor de todo esforço absorvido pelo pavimento.

A estrutura do pavimento acima do subleito é formada por uma regularização do subleito, um reforço de subleito, caso seja necessário, uma Sub-base sobre esse reforço de subleito, revestida por uma base e finalizada por um revestimento. A Figura 1 mostra uma estrutura-tipo de pavimento, com as camadas anteriormente descritas. 
Figura 1 - Estrutura de pavimento-tipo

\begin{tabular}{|l|}
\hline Revestimento asfáltico \\
\hline Base \\
\hline Sub-base \\
\hline Reforço do subleito \\
Subleito \\
\hline
\end{tabular}

Fonte: Bernucci et al. (2006).

\subsubsection{Serviços}

Os tipos de serviço prestados em uma rodovia são muito diversos, como por exemplo: a pintura de ligação, que se trata de uma aplicação de uma substância conhecida como ligante asfáltica do tipo RR-1C sobre o revestimento ou base, antecedendo à execução de uma camada asfáltica, gerando uma condição de aderência, entre esta e o revestimento a ser feito, segundo a definição do DNIT.

Outro serviço comum é a chamada imprimação, que consiste na utilização da emulsão asfáltica do tipo EAI, ou o asfalto diluído, tipo CM-30, sobre a base concluída, antecedente ao revestimento asfáltico, impermeabilizando, possibilitando condições de aderência entre esta e o revestimento a ser feito, e também conferir qualquer coesão superficial que possa existir.

Apesar de não ocorrer necessariamente em todas as obras de pavimentação, a frenagem é utilizada em casos em que há um pavimento pré-existente, também é necessário fresar a pista para a constituição de um novo pavimento, ou de nova camada. É realizado o desbaste, ou corte de camadas do pavimento as asfáltico por meio do processo mecânico a frio, segundo a DNIT.

O conhecimento adequado dos elementos, a partir de sua avaliação e também caracterização é de extrema importância na dosagem de uma mistura asfáltica, para que se seja possível distinguir a combinação de materiais (agregado e Material Asfáltico) e então obter um resultado que garanta que o pavimento tenha um bom desempenho. Uma função de dosagem feita de maneira inadequada gera uma série de insucessos, por isso a importância de compreender as características e propriedades das misturas. 


\subsection{Principais tipos de Pavimento Rodoviário}

O pavimento rodoviário classifica-se tradicionalmente em dois tipos básicos: rígidos e flexíveis. Mais recentemente há uma tendência de usar-se a nomenclatura pavimentos de concreto de cimento Portland (ou simplesmente concreto-cimento) e pavimentos asfálticos, respectivamente, para indicar o tipo de revestimento do pavimento.

\subsubsection{Pavimentação Flexível ou asfáltica}

Quando as camadas do pavimento sofrem algum tipo de deformação elástica ao receberem qualquer tipo de carregamento aplicado, temos a pavimentação flexível, nele suas cargas são distribuídas parcialmente equivalentes entre as camadas. (DNIT, 2006).

Neste tipo de pavimentação são utilizados os seguintes materiais: agregados graúdos que são compostos por seixos rolados ou pedras, material asfáltico que são os aglutinantes, e os agregados miúdos que são compostos por pó de pedra ou areia. Para a confecção da pavimentação flexível, são necessários três processos: primeiro ocorre a imprimação, depois o lançamento do CBUQ e pôr fim a compressão e compactação.

Segundo Balbo (2007), é o pavimento no qual a absorção de esforços dá-se de forma dividida entre várias camadas, encontrando-se as tensões verticais em camadas inferiores, concentradas em região próxima da área de aplicação da carga.

Figura 2 - Estrutura de um pavimento flexível

\section{FLEXÍVEL}

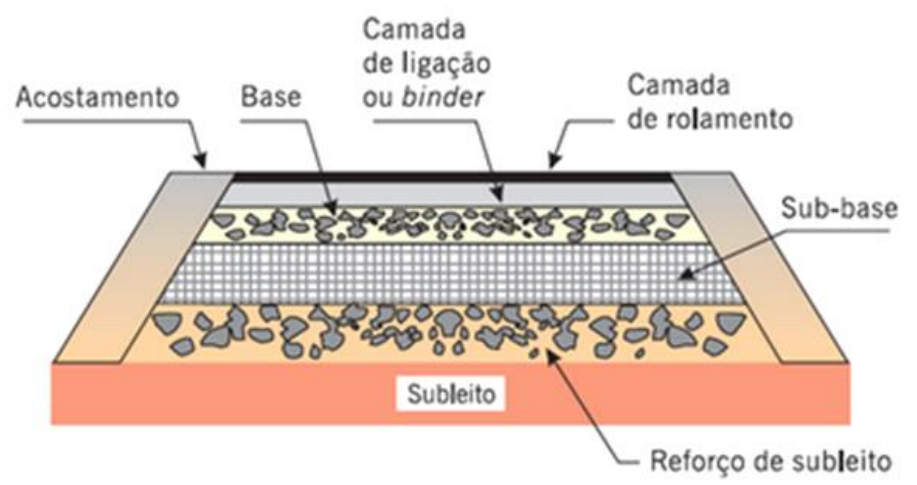

Fonte: http://www.sptsondagens.com.br/servicos?servico=dimensionamento 


\subsubsection{Pavimentação Rígida ou em concreto}

A pavimentação rígida é toda pavimentação cuja rigidez é muito elevada em relação às camadas inferiores, absorvendo assim todas as tensões que advém do carregamento nela aplacada. (DNIT, 2006)

Podendo ser extremamente resistente, o revestimento é feito com cimento Portland, podendo ou não apresentar uma camada de sub-base entre o revestimento e o subleito, mas para isso depende da qualidade do material existente no subleito. Para Balbo (2007), este é o pavimento onde uma camada absorve a maior parte da parcela de esforços horizontais, gerando, consequentemente, pressões verticais aliviadas e bem distribuídas em cima das camadas inferiores.

Figura 2 - Estrutura de um pavimento flexível

RÍGIDO

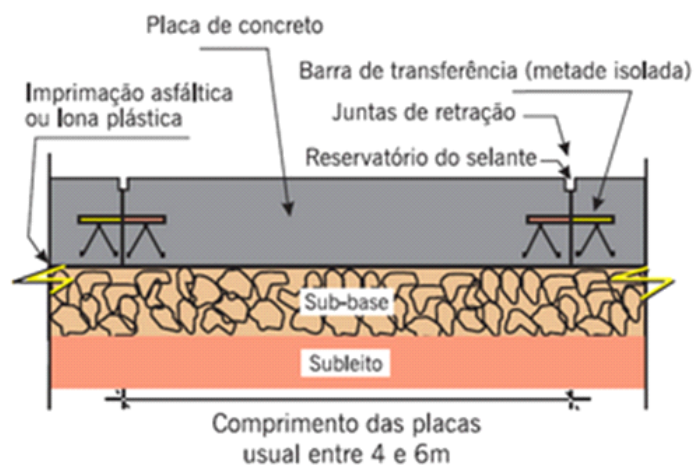

Fonte: http://www.sptsondagens.com.br/servicos?servico=dimensionamento Existem vários tipos de pavimentos rígido, dentre eles estão:

- Pavimento de concreto simples: É o pavimento de concreto Portland, em que são contidas pelo próprio concreto todas as tensões solicitantes, com ausência de qualquer armadura distribuída (Não podem ser consideradas armaduras eventuais sistemas de ligação de transferência de carga entre as placas constituídas pelas juntas transversais e longitudinais).

- Pavimentação do tipo Whitetopping: Nesse tipo de pavimentação, um pavimento já existente é flexível servirá como uma sub-base, sendo sobreposto por um novo. Geralmente usado em situações como, por exemplo: o processo de recuperação de estradas desgastadas. Não são utilizadas armaduras na constituição desse tipo de pavimentação, já que as tensões são suportadas pelo próprio concreto, sendo usado 
armaduras para sistemas se transmissões entre placas, em alguns casos.

- Pavimentação estruturalmente armada: Neste tipo de pavimento, é utilizada uma armadura em sua estrutura. Sua função é direcionada a conter as tensões de tração na flexão que se formam sobre a placa. Nesse tipo de pavimentação, a armação tende a ser colocada na região inferior às placas, onde deve ocorrer maior concentração de reforço.

- Pavimentação de concreto rolado: Para locais onde há circulação de veículos que transitam em baixa velocidade, indica-se o concreto compactado, também conhecido por concreto rolado, que evita futuros desgastes e deformações, uniformizando o suporte, de acordo com a ABCP (Associação Brasileira de Concreto Portland). É usado em construções como pátios de manobras, rodovias ou estacionamentos. Também usado no desenvolvimento de sub-bases, como fora feito no Rodoanel Mário Covas, em São Paulo.

- Pavimentação com peças em concreto pré-moldadas: As movimentações formadas por peças pré-moldadas podem ser feitas nas mais variadas formas, junta postos com ou sem a presença de articulações rejuntadas com asfalto. A pavimentação com peças em concreto pré-moldadas é indicada para locais tais como estacionamentos ou desvios de tráfego leve.

\section{Metodologia}

Este trabalho foi desenvolvido com análise qualitativa em forma de pesquisa documental e procedimentos técnicos bibliográficos através das técnicas de pesquisa bibliográfica desenvolvendo o conhecimento a partir de diversos tipos de publicações, como livros, artigos e sites acadêmicos. A revisão possibilitará conhecer o que já existentes sobre o assunto e as diferentes formas de análise a serem realizadas.

Ainda foram utilizadas algumas bases de dados virtuais como Portal CAPES (Coordenação de Aperfeiçoamento de Pessoal da Saúde), SCIELO (Scientific Electronic Library Online) e o Google Acadêmico. Escolheu-se essas bibliotecas virtuais, pelo fato de as mesmas abrangerem uma coleção variada de trabalhos, artigos, notícias e reportagens científicas que expressam confiabilidade acadêmica. Ainda foram realizadas consultas a materiais impressos, principalmente livros de grandes doutrinadores acerca do assunto. 
Posterior à leitura criteriosa das diversas fontes cientificas, foi feita uma organização das ideias e informações colhidas, fazendo assim um Artigo de Revisão Bibliográfica, onde procurou-se abordar as informações mais importantes para a compreensão do trabalho. Para isso foi necessário fazer uma interpretação entre linhas de todos os assuntos abordados, buscando correlacionar o passado com a atualidade utilizando das matérias acadêmicas ministradas durante o curso, para fornecer pontos de vista pessoais, porém técnicos, enfim, mencionar todas as percepções do fenômeno estudado de forma abrangente e impessoal possível.

\section{Resultados e Discussão}

A pavimentação rígida mostra-se ser mais vantajosa, destacando-se por seus aspectos positivos. Sua resistência proporciona uma maior segurança para motoristas em pistas molhadas, ao contrário da Pavimentação Flexível, cuja superfície de torna escorregadia, tornando-a propícia a causar acidentes, assim como sua coloração escura, que dificulta a visibilidade em períodos noturnos, além de contribuir para os gastos em energia elétrica, e com a degradação do meio ambiente, levando em conta que um dos principais elementos utilizados em sua produção é o petróleo, além do consumo de óleo, que o torna ambientalmente desfavorável; ao contrário do pavimento rígido, cuja coloração clara contribui para uma melhor visão da pista, seja durante a noite ou em períodos chuvosos.

É também composto por matérias locais, utilizando apenas a energia elétrica, sendo assim, considerada uma opção ambientalmente mais favorável. A pavimentação flexível também retém e absorve a umidade, também se degrada facilmente sobre influência de mudanças de temperaturas ou chuvas constantes, tendo sua durabilidade reduzida para 10 anos. Apesar disso, essa pavimentação específica, não necessita de juntas de dilatação, possui uma melhor sinalização e durabilidade em sua tinta, além de ser a opção de menor custo.

Embora se mostre a opção mais econômica, a pavimentação flexível possui uma série de aspectos defeituosos, que tornam a pavimentação rígida a melhor opção dentre as duas, já que seus pontos positivos a coloca a frente, em destaque para a sua durabilidade, que demonstra ser o dobro que o pavimento flexível. 
Além disso, o pavimento de concreto contem elevada resistência mecânica quanto aos seus aspectos relacionados ao desgaste, sendo que o mesmo não oxida, não tende a deformar plasticamente, raramente forma trilhas de rodas e buracos, o que acaba por garantir uma elevada durabilidade, ainda requerer pouca manutenção, diminuindo assim os riscos de acidentes relacionados as condições da rodovia.

Devida a sua coloração clara, uma das suas maiores vantagens, existe a possibilidade de reflexão da luz, o que melhora a visibilidade para os motoristas que transitam pela via, especialmente à noite ou em dias chuvosos. Devida a sua capacidade de reflexão, ocorre uma economia de iluminação pública. Ainda devido a sua coloração mais clara, a temperatura do ambiente se torna mais baixa que a temperatura no asfalto, o que gera economia para o motorista que gasta menos com ar condicionado e consequentemente gera manos calor nas cidades.

Com uma resistência maior quando se fala em derrapagens, a pavimentação de concreto, gera uma menor possibilidade de derrapagens e tombamento dos veículos pelo fato de ter uma inclinação da secção transversal que é de 2 a 3 vezes menor que a que é feita nos pavimentos flexíveis.

O pavimento de concreto ainda tem o benefício da aderência dos pneus, pois a sua superfície de rolamento é bastante elevada, o que permite uma considerável redução na distância da frenagem. Ainda existe uma economia de combustível, quando falamos das superfícies rígidas, pois devido a sua menor resistência ao rolamento, é feito menos esforço da parte mecânica dos veículos, e consequentemente se gera uma economia visível de combustível.

Ao falarmos dos custos iniciais da construção da pavimentação de concreto, vimos que ela tem se tornado cada vez mais competitivo, o que faz com que os custos finais da pavimentação sejam reduzidos, além de aumentar o uso de novas tecnologias e equipamentos de ponta para aperfeiçoar o serviço e deixa-lo mais barato.

Como o custo da pavimentação não inclui apenas a sua colocação no leito da estrada deve-se levar em conta o quanto de gastará futuramente para mantê-lo, e conserva-lo. É preciso fazer um cálculo do investimento considerando os custos para construção e consequentemente para manutenção. Estimasse que o pavimento de concreto chegue a ser $61 \%$ mais barato que os outros alternativos. 


\section{Conclusão}

De fundamental importância para um país, as rodovias são as principais responsáveis pelas mudanças culturais ocorridas, pois ela atinge praticamente todos os pontos do território nacional, possuindo uma grande relevância na atividade econômica nacional. O estado de conservação da superfície do pavimento é um dos elementos de mais fácil percepção ao usuário da rodovia, pois os defeitos e irregularidades nessa superfície afetam o seu conforto e a segurança ao rolamento do tráfego, bem como diminuem a durabilidade dos componentes veiculares. Por esses e outros motivos é necessária uma boa pavimentação nos asfaltos.

Conclui-se, por tanto que as condições das rodovias interferem diretamente no nosso dia a dia, e por tanto é necessário que elas estejam conservadas, pois devido a realidade precária de muitas vias brasileiras e a importância econômica que as mesmas representam, deve se avaliar a viabilidade de utilização de matérias que durem mais tempo e tragam um custo/benefício para todos.

\section{Referências}

BALBO, José Tadeu. Pavimentação Asfáltica: materiais, projeto e restauração. São Paulo: Oficina de Textos, 2007.

BERNUCCI, Liedi Bariani et al. Pavimentação asfáltica: formação básica para engenheiros. Rio de Janeiro: PETROBRÁS/ ABEDA, 2006.

BRASIL, Ministério dos Transportes. Diretoria de Planejamento e Pesquisa. Instituto de Pesquisas Rodoviárias. DNIT 095/2006 EM: cimento asfáltico de petróleo especificação de material. Rio de Janeiro: 2006. Disponível em: $<$ http://www1.dnit.gov.br/ipr_new/normas/especificacaomaterial.htm> Acesso em: 25 set. 2019.

CNT - Confederação Nacional dos Transportes. Pesquisa Rodoviária, 2007.

DNIT. Manual de Pavimentação. 3. ed. Rio de Janeiro, 2006. 
PINTO, S. PREUSSLER, E. Pavimentação Rodoviária - Conceitos Fundamentais sobre Pavimentos Flexíveis. Rio de Janeiro, 2ª ed. 269p. 2002.

PINTO, S; PINTO, I. E. Pavimentação Asfáltica: Conceitos Fundamentais sobre Materiais e Revestimentos Asfálticos. 1. ed. Rio de Janeiro: LTC, 2015.

QUINTIERE, Andréa. Primeira rodovia pavimentada no Brasil comemora hoje 150 anos. 2011. Disponível em <http://memoria.ebc.com.br/agenciabrasil/noticia/2011-0623/primeira-rodovia-pavimentada-no-brasil-comemora-hoje-150-anos>. Acessado em: 19 de set. de 2019.

CATULÉ, Pablo Fernandes et al. Estudo de verificação da viabilidade de captação e uso de água da chuva no município de Teófilo Otoni-MG. Research, Society and Development, v. 7, n. 11, p. e6711438-e6711438, 2018.

GOMES, Jarbas Herinson Dias et al. Análise Comparativa Do Sistema Construtivo De Alvenaria Convencional E Sistema Construtivo De Alvenaria Estrutural Em Uma Casa Térrea Em Teófilo Otoni. Revista Multidisciplinar do Nordeste Mineiro-Unipac ISSN, v. 2178, p. 6925, 2018.

SIQUEIRA, Rodrigo Alves et al. Análise Comparativa Entre O Concreto Usinado E O Concreto Produzido No Canteiro De Obra. Revista Multidisciplinar do Nordeste Mineiro-Unipac ISSN, v. 2178, p. 6925, 2018. 